\title{
Non-steroidal anti-inflammatory drugs among chronic kidney disease patients: an epidemiological study
}

\author{
Samar Abd ElHafeez ${ }^{*}$, Reem Hegazy ${ }^{2}$, Yasmine Naga ${ }^{3}$, Iman Wahdan ${ }^{1}$ and Sunny Sallam
}

\begin{abstract}
Background: Non-steroidal anti-inflammatory drugs (NSAIDs) should be avoided among chronic kidney disease (CKD) patients. Till now, limited data are available on NSAID use in Egypt, and we aimed to study the prevalence and pattern of NSAID use among CKD patients.

Methods: A cross-sectional study was done among 350 CKD adult patients presented to the Main Alexandria University Hospital. Those with end-stage renal disease and diagnosed with acute renal injury and pregnant women were excluded. Demographic and clinical data were collected by interviewing eligible patients. Data about the pattern, history of drug-drug interactions, and knowledge about the NSAID side effects were also gathered.

Results: Of the enrolled patients, 57.1\% were hypertensive, 46\% were diabetics, 28\% had osteoarthritis, and 18.3\% had cardiovascular disease. CKD stages were 3.7\%, 40.3\%, and 56\% in stages 2, 3, and 4, respectively. Almost two thirds (65.7\%) were NSAID users. Among them, $82.6 \%$ were regular users. Headache was the most reported (68.7\%) reason of use. The use of drugs which may have drug-drug interaction with the NSAIDs (as diuretics or renin-angiotensin-aldosterone system inhibitors) was reported in 36\%. In multiple logistic regression, the odds of NSAID use decreased by $4 \%$ (odds ratio $(\mathrm{OR})=0.96,95 \%$ confidence interval $(\mathrm{Cl}) 0.93-0.99, p=0.01$ ) for every year increase in the patient's age and decreased by $3 \%(\mathrm{OR}=0.97,95 \% \mathrm{Cl} 0.95-0.99, p=0.01)$ for every $1 \mathrm{ml} / \mathrm{min} / 1.73 \mathrm{~m}^{2}$ increase in glomerular filtration rate.

Conclusion: Despite the hazards of NSAID use on the kidney, still high proportion of CKD patients are using them for a long period and they are simultaneously using other drugs with possible drug-drug interactions. This study provided important information that would decrease the gap in knowledge about the use of NSAID in Egypt. It is recommended that NSAIDs should be used with caution among CKD patients and patients should be advised about its adverse health consequences.
\end{abstract}

Keywords: NSAIDs, CKD, Epidemiology

\section{Introduction}

Both over-the-counter and prescribed non-steroidal anti-inflammatory drugs (NSAIDs) are widely used all over the world. Although it is commonly used for the management of inflammation and pain, several guidelines including the Kidney Disease Initiative Global Outcome (KDIGO) guidelines recommended avoidance of NSAIDs (except aspirin and acetaminophen) for most patients with chronic kidney disease (CKD) [1].

\footnotetext{
* Correspondence: samarabdelhafeez.epid@gmail.com

${ }^{1}$ Department of Epidemiology, High Institute of Public Health, Alexandria

University, 165 ElHorreya Avenue, ElHadara, Alexandria, Egypt

Full list of author information is available at the end of the article
}

The use of NSAIDs has been associated with renal function deterioration through variable mechanisms including alteration of the intraglomerular hemodynamic, nephrotic syndrome, glomerulonephritis, chronic interstitial nephritis, renal papillary necrosis, hyperkalemia, and podocyte injury [2-4]. This could lead to renal impairment and worsen the degree of renal dysfunction in CKD patients up to the development of end-stage renal disease (ESRD) [5]. Persons with CKD, however, are likely unaware of their disease and may also be unaware that NSAIDs should be avoided. Additionally, those with CKD are likely to be older and have multiple comorbid conditions or symptoms that lead to increased use of NSAIDs [6]. 
Table 1 Characteristics of the study CKD patients, Alexandria Main University Hospital, Egypt, 2016

\begin{tabular}{|c|c|c|c|c|}
\hline Characteristics & $\begin{array}{l}\text { Total }(n=350) \\
\text { No. }(\%)\end{array}$ & $\begin{array}{l}\text { NSAID users }(n=230) \\
\text { No. }(\%)\end{array}$ & $\begin{array}{l}\text { NSAID non-users }(n=120) \\
\text { No. }(\%)\end{array}$ & $p$ value \\
\hline \multicolumn{5}{|l|}{ I. Personal characteristics } \\
\hline Age (years) Mean \pm SD & $55 \pm 13$ & $54 \pm 13$ & $57 \pm 13$ & 0.06 \\
\hline \multicolumn{5}{|l|}{ Gender } \\
\hline Male & $180(51.4)$ & $105(45.7)$ & $75(62.5)$ & \multirow[t]{2}{*}{$0.003^{*}$} \\
\hline Female & $170(48.6)$ & $125(54.3)$ & $45(37.5)$ & \\
\hline \multicolumn{5}{|l|}{ Marital status } \\
\hline Unmarried & $17(4.9)$ & $12(5.2)$ & $5(4.2)$ & \\
\hline Married & $261(74.5)$ & $169(73.5)$ & $92(76.7)$ & \multirow[t]{2}{*}{0.64} \\
\hline Else & 72(20.6) & $49(21.3)$ & 23(19.1) & \\
\hline \multicolumn{5}{|l|}{ Education } \\
\hline Illiterate & $223(63.7)$ & $136(59.2)$ & $87(72.5)$ & \\
\hline School education & $116(33.1)$ & $86(37.3)$ & $30(25.0)$ & \multirow[t]{2}{*}{0.13} \\
\hline University & $11(3.2)$ & $8(3.5)$ & $3(2.5)$ & \\
\hline \multicolumn{5}{|l|}{ Occupation } \\
\hline Not working & $206(58.8)$ & $145(63)$ & $61(50.8)$ & \\
\hline Clerk & $29(8.3)$ & $23(10)$ & $6(5)$ & \multirow[t]{3}{*}{$0.003^{*}$} \\
\hline Worker & $42(12)$ & $27(11.7)$ & $15(12.5)$ & \\
\hline Retired & $73(20.9)$ & $35(15.3)$ & $38(31.7)$ & \\
\hline \multicolumn{5}{|l|}{ Smoking status } \\
\hline Never smoker & $207(59.2)$ & $146(63.5)$ & $61(50.8)$ & \multirow[t]{3}{*}{$0.02^{*}$} \\
\hline Current smoker & $67(19.1)$ & $44(19.1)$ & 23(19.2) & \\
\hline Former smoker & $76(21.7)$ & $40(17.4)$ & $36(30)$ & \\
\hline \multicolumn{5}{|l|}{ Weight categories } \\
\hline Normal & $54(15.4)$ & $34(14.8)$ & $20(16.7)$ & \multirow[t]{3}{*}{0.85} \\
\hline Overweight & $149(42.6)$ & $100(43.5)$ & 49 (40.8) & \\
\hline Obese & $147(42)$ & $96(41.7)$ & $51(42.5)$ & \\
\hline \multicolumn{5}{|l|}{ II. Comorbid diseases } \\
\hline \multicolumn{5}{|l|}{ Hypertension } \\
\hline Yes & $200(57.1)$ & $146(63.5)$ & $54(45)$ & \multirow[t]{2}{*}{$0.001^{*}$} \\
\hline No & $150(42.9)$ & $84(36.5)$ & $66(55)$ & \\
\hline \multicolumn{5}{|l|}{ Diabetes } \\
\hline Yes & $161(46)$ & $105(45.7)$ & $56(46.7)$ & \multirow[t]{2}{*}{0.86} \\
\hline No & $189(54)$ & $125(54.3)$ & $64(53.3)$ & \\
\hline \multicolumn{5}{|l|}{ Osteoarthritis } \\
\hline Yes & $98(28)$ & $82(35.7)$ & $16(13.3)$ & \multirow[t]{2}{*}{$<0.001^{*}$} \\
\hline No & $252(72)$ & $148(64.3)$ & $104(86.7)$ & \\
\hline \multicolumn{5}{|c|}{ Autoimmune disease (RA and SLE) } \\
\hline Yes & $17(4.9)$ & $15(6.5)$ & $2(1.7)$ & \multirow[t]{2}{*}{0.05} \\
\hline No & $333(95.1)$ & $219(93.5)$ & $118(98.3)$ & \\
\hline \multicolumn{5}{|l|}{ CVDs } \\
\hline Yes & $64(18.3)$ & $42(18.3)$ & $22(18.3)$ & \multirow[t]{2}{*}{0.99} \\
\hline No & $286(81.7)$ & $188(81.7)$ & $98(81.7)$ & \\
\hline
\end{tabular}

Hepatitis C virus 
Table 1 Characteristics of the study CKD patients, Alexandria Main University Hospital, Egypt, 2016 (Continued)

\begin{tabular}{|c|c|c|c|c|}
\hline Characteristics & $\begin{array}{l}\text { Total }(n=350) \\
\text { No. }(\%)\end{array}$ & $\begin{array}{l}\text { NSAID users }(n=230) \\
\text { No. }(\%)\end{array}$ & $\begin{array}{l}\text { NSAID non-users }(n=120) \\
\text { No. }(\%)\end{array}$ & $p$ value \\
\hline Yes & $58(16.6)$ & $23(10)$ & $35(29.2)$ & $<0.001^{*}$ \\
\hline No & $292(83.4)$ & $207(90)$ & $85(70.8)$ & \\
\hline \multicolumn{5}{|l|}{ Cancer } \\
\hline Yes & $13(3.7)$ & $11(4.8)$ & $2(1.7)$ & 0.23 \\
\hline No & $337(96.3)$ & $219(95.2)$ & $118(98.3)$ & \\
\hline \multicolumn{5}{|l|}{ Kidney stone } \\
\hline Yes & $9(2.6)$ & $7(3)$ & $2(1.7)$ & 0.72 \\
\hline No & $341(97.4)$ & $223(97)$ & $118(98.3)$ & \\
\hline \multicolumn{5}{|l|}{ III. Chronic kidney disease } \\
\hline \multicolumn{5}{|l|}{ eGFR $\left(\mathrm{ml} / \mathrm{min} / 1.73 \mathrm{~m}^{2}\right)$} \\
\hline Median (inter-quartile range) & $27(18-37)$ & $26(18-34)$ & $31(19-44.75)$ & $0.003^{*}$ \\
\hline \multicolumn{5}{|l|}{ CKD stage } \\
\hline Stage 2 & $13(3.7)$ & $6(2.6)$ & $7(5.8)$ & \\
\hline Stage $3 a$ & $44(12.6)$ & $21(9.1)$ & 23(19.2) & $0.007^{*}$ \\
\hline Stage $3 b$ & $97(27.7)$ & $62(27)$ & $35(29.2)$ & \\
\hline Stage 4 & $196(56.0)$ & $141(61.3)$ & $55(45.8)$ & \\
\hline \multicolumn{5}{|c|}{ IV. History of intake of selected interacting drugs with NSAIDs } \\
\hline Diuretics & $34(9.7)$ & $19(8.3)$ & $8(6.7)$ & 0.20 \\
\hline RAAS inhibitors & $70(20)$ & $53(23)$ & $17(14.2)$ & $0.04^{*}$ \\
\hline Both & $22(6.3)$ & $14(6.1)$ & $8(6.7)$ & 0.83 \\
\hline
\end{tabular}

SD standard deviation, RA rheumatoid arthritis, SLE systemic lupus erythmatosus, CVDs cardiovascular diseases, eGFR estimated glomerular filtration rate, CKD chronic kidney disease, RAAS renin-angiotensin-aldosterone inhibitors, NSAIDs non-steroidal anti-inflammatory drugs

*Significant at $p<0.05$

In addition, NSAIDs interact unfavorably with some commonly prescribed medications, including loop diuretics and renin-angiotensin-aldosterone system (RAAS) inhibitors. This is referred to as "triple whammy, leading to reduced effectiveness, along with increased risk of renal impairment. Although epidemiologic studies have linked NSAID use to progressive CKD, the risks of NSAIDs in patients with CKD, while supported by consensus and theoretical effect, remain less clearly established by evidence [7].

Despite the adverse effects of NSAIDs on renal functions, the available data on its pattern among CKD patients in Egypt is minimal. This study aimed to estimate the prevalence, to identify the pattern of NSAID use, and to assess the knowledge about their adverse effects in CKD patients. This will help in setting plans to reduce NSAID use in CKD patients, and spread awareness of their potential harms in this population.

\section{Materials and methods}

\subsection{Study setting}

The study was conducted in the outpatient clinics and the inpatient wards of the Internal Medicine Department, Alexandria Main University Hospital, which is the tertiary referral hospital for all patients from four governorates (Alexandria, El Beheira, Kafr-El Sheikh, and Marsa Matrouh).

\subsection{Study design}

A cross-sectional study was carried out.

\subsection{Study population}

Adult (18+ years) CKD patients diagnosed in pre-ESRD (i.e., before dialysis or transplantation) were included in the study. Patients $<18$ years of age; those who were in stage 5 CKD (ESRD), on dialysis, with previous renal transplantation, and with acute renal injury; and pregnant women were excluded from the study.

\subsection{Sample size and sampling techniques}

The sample size was determined using Epi-info software 7.2.2.6 (CDC, 2018) based on power 80\%, with confidence level of $95 \%$ and prevalence of using NSAIDs among CKD patients of $65.8 \%$ [8]. The minimum required sample size was 340 patients. The sample was rounded to 350 patients. Patients were consecutively included on daily basis from the outpatient clinics and the inpatient wards until the required sample was reached. 


\subsection{Data collection}

A predesigned interview questionnaire was used to collect data from the patients about their personal characteristics (sociodemographic characteristics and smoking), history of comorbid diseases, history of selected drugs interacting with NSAIDs (For patients who were illiterate, the researchers had to show them the boxes of the drugs to know which one is taken.), and NSAID use including the type, purpose, pattern, and source of advice. In addition, knowledge about the adverse effects of NSAIDs was determined.

Concerning smoking, patients were classified into never smokers (those who have not smoked 100 cigarettes during their lifetime), current smokers (those who report smoking at least 100 cigarettes in their lifetime and who smoke cigarettes every day or some days), and former smokers (those who has smoked at least 100 cigarettes in their lifetime but does not smoke cigarettes) [9].

Blood pressure, weight, and height were measured, and standardized serum creatinine was collected from the patients' records.

Regarding weight, patients were classified according to body mass index (BMI) [10] (weight in kilograms/height in meters $\left.^{2}\right)$ into underweight $\left(<18.5 \mathrm{~kg} / \mathrm{m}^{2}\right)$, normal weight $\left(18.5-24.9 \mathrm{~kg} / \mathrm{m}^{2}\right)$, overweight $\left(25-29.9 \mathrm{~kg} / \mathrm{m}^{2}\right)$, and obese $\left(\geq 30 \mathrm{~kg} / \mathrm{m}^{2}\right)$.

The estimated glomerular filtration rate (eGFR) was calculated by CKD-EPI equation [11]

$$
\begin{aligned}
\mathrm{eGFR}=141 & \times \min (\mathrm{Scr} / \kappa, 1)^{\alpha} \times \max (\mathrm{Scr} / \kappa, 1)^{-1.209} \\
& \times 0.993^{\mathrm{age}} \times 1.018[\text { if female }]
\end{aligned}
$$

where Scr is serum creatinine $(\mathrm{mg} / \mathrm{dl}), \kappa$ is 0.7 for females and 0.9 for males, $\alpha$ is -0.329 for females and 0.411 for males, min indicates the minimum of $\mathrm{Scr} / \kappa$ or 1 , and max indicates the maximum of $\mathrm{Scr} / \kappa$.

CKD was defined according to the 2012 KDIGO guidelines [1] according to the presence of the following criteria for more than 3 months:

1. Markers of kidney damage (one or more)

- Albuminuria (AER $\geq 30 \mathrm{mg} / 24 \mathrm{~h} ; \mathrm{ACR} \geq 30 \mathrm{mg} / \mathrm{g}$ [ $\geq 3 \mathrm{mg} / \mathrm{mmol}])$

- Urine sediment abnormalities

- Electrolyte and other abnormalities due to tubular disorders

- Abnormalities detected by histology

- Structural abnormalities detected by imaging

- History of kidney transplantation

2. Decreased GFR (GFR $<60 \mathrm{ml} / \mathrm{min} / 1.73 \mathrm{~m}^{2}$ (GFR categories G3a-G5))

CKD is classified into the following stages:
G1: normal or high GFR $\left(>90 \mathrm{ml} / \mathrm{min} / 1.73 \mathrm{~m}^{2}\right)$

G2: mild decrease in GFR $\left(60-89 \mathrm{ml} / \mathrm{min} / 1.73 \mathrm{~m}^{2}\right)$

G3a: mild to moderate decrease in GFR $(45-59 \mathrm{ml} /$ $\min / 1.73 \mathrm{~m}^{2}$ )

G3b: moderate to severe decrease in GFR (30-44 ml/ $\min / 1.73 \mathrm{~m}^{2}$ )

G4: severe decrease in GFR $\left(15-29 \mathrm{ml} / \mathrm{min} / 1.73 \mathrm{~m}^{2}\right)$

G5: kidney failure $($ GFR $<15)$

We excluded patients in CKD stage 5 as those patients already reached ESRD and so prevention of NSAID use will not add any benefits to the disease progression.

\subsection{Statistical analysis}

Data was summarized using mean $\pm \mathrm{SD}$, medians and inter-quartile ranges or frequencies and percentage, as appropriate. Comparison between the variables was done using $t$ test, Mann-Whitney or chi-square according to the data type. Correlation between the renal function and duration of NSAID use was done by Pearson's correlation. The factors associated with the use of NSAIDs were identified using multiple logistic regression analysis. The model included all variables which were significantly related to NSAID use in bivariate analysis. Results are considered significant when $p<0.05$.

\section{Results}

Table 1 summarizes the baseline characteristics of the study patients. The mean \pm SD age of the study participants $(N=350)$ was $55 \pm 13$ years, $51 \%$ were males, $74.5 \%$ were married, $40.8 \%$ were smokers, $42 \%$ were obese, $57.1 \%$ were hypertensive, $46 \%$ were diabetics, $18.3 \%$ had cardiovascular disease, and $4.9 \%$ had autoimmune disease. More than half $(56 \%)$ of the patients were in stage 4 CKD, and $40.3 \%$ were in stage 3 CKD. One fifth $(20 \%)$ of the patients gave history of RAAS inhibitor use, 9.7\% were using diuretics, and 6.3\% reported the use of both.

\subsection{Prevalence and pattern of NSAID use}

About two thirds (65.7\%) of the study patients reported NSAID use (Fig. 1). Patients who use NSAIDs were younger, females, non-smokers, and hypertensive; had

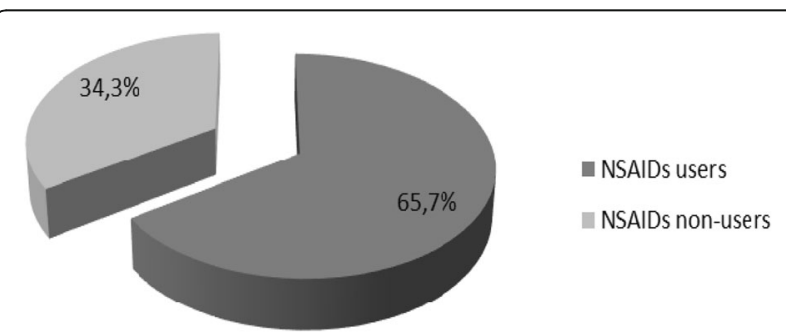

Fig. 1 Prevalence of NSAID use among the study CKD patients 
osteoarthritis; and were more users of RAAS inhibitors (Table 1).

Among NSAID users, ketoprofen was the most commonly used (50.3\%), followed by diclofenac (33.7\%), ibuprofen $(23.1 \%)$, ketorolac $(2.6 \%)$, and meloxicam $(2.3 \%)$ (Table 2). More than two thirds (68.7\%) of the patients reported headache as the main reason of NSAID use,

Table 2 NSAID use by the study CKD patients (Alexandria Main University Hospital, Egypt, 2016)

\begin{tabular}{|c|c|c|}
\hline NSAID use & Frequency $(n=230)$ & Percent \\
\hline \multicolumn{3}{|l|}{ Types of NSAIDs ${ }^{a}$} \\
\hline Ketoprofen & 176 & 50.3 \\
\hline Diclofenac & 118 & 33.7 \\
\hline Ibuprofen & 81 & 23.1 \\
\hline Ketorolac & 9 & 2.6 \\
\hline Meloxicam & 8 & 2.3 \\
\hline \multicolumn{3}{|l|}{ Purpose of use $\mathrm{a}^{\mathrm{a}}$} \\
\hline Headache & 158 & 68.7 \\
\hline Generalized pain & 114 & 49.6 \\
\hline Joint pain & 101 & 43.9 \\
\hline Renal colic & 26 & 11.3 \\
\hline Dental pain & 23 & 10.0 \\
\hline Menstrual pain & 3 & 1.3 \\
\hline \multicolumn{3}{|l|}{ Pattern of use } \\
\hline \multicolumn{3}{|c|}{ Frequency of NSAID use within last month } \\
\hline Once a week & 40 & 17.4 \\
\hline Twice a week & 92 & 40.0 \\
\hline Three times a week & 47 & 20.4 \\
\hline Every day & 51 & 22.2 \\
\hline \multicolumn{3}{|l|}{ Duration of NSAID use } \\
\hline$<1$ year & 28 & 12.2 \\
\hline $1-3$ years & 96 & 41.7 \\
\hline$>3$ years & 106 & 46.1 \\
\hline \multicolumn{3}{|l|}{ Regular use } \\
\hline Yes & 190 & 82.6 \\
\hline No & 40 & 17.4 \\
\hline \multicolumn{3}{|c|}{ Number of NSAIDs used within last month } \\
\hline One type & 103 & 44.8 \\
\hline Two types & 92 & 40.0 \\
\hline Three types & 31 & 13.5 \\
\hline More than three & 4 & 1.7 \\
\hline \multicolumn{3}{|c|}{ Route of administration within last month } \\
\hline Oral & 171 & 74.3 \\
\hline Injection & 2 & 0.9 \\
\hline Both & 57 & 24.8 \\
\hline
\end{tabular}

NSAIDs non-steroidal anti-inflammatory drugs

${ }^{\mathrm{a}}$ Non-mutually exclusive followed by generalized pain (49.6\%) and joint pain (43.9\%). Forty percent of NSAID users used NSAIDs twice a week, $20.4 \%$ three times a week, and $22 \%$ every day within the last month. More than $80 \%(82.6 \%)$ of NSAID users gave history of regular use (at least twice a week for more than 2 months). More than $40 \%$ of the NSAID users used NSAIDs for a period exceeding 3 years or from 1 to 3 years $(46.1 \%$ and $41.7 \%$, respectively) (Table 2). There was an inverse correlation between the eGFR and the duration of NSAID use $(r=-$ $0.25, p<0.001$ ) (Fig. 2).

The majority of NSAID users (76.5\%) used NSAIDs by self-decision, while $25.2 \%$ used them after the advice of physicians. Those who mentioned relatives and friends constituted 13.5\%. Pharmacists and previous prescription constituted $10.4 \%$ and $9.1 \%$, respectively.

\subsection{Knowledge about adverse effects of NSAIDs}

More than half (53.2\%) of CKD patients did not know whether NSAIDs have adverse effects or not. Those who mentioned that NSAIDs have adverse effects constituted $37.1 \%$, and only $9.7 \%$ said that NSAIDs have no adverse effects. Among CKD patients who mentioned that NSAIDs have adverse effects, $55.4 \%$ thought that NSAIDs cause kidney problems. The patients who mentioned that NSAIDs lead to gastrointestinal tract, liver problems, and heart problems constituted $45.4 \%, 19.2 \%$, and $2.3 \%$, respectively (Table 3 ).

\subsection{Factors affecting NSAID use among CKD patients}

Multiple logistic regression analysis of the factors affecting NSAID use among CKD patients revealed that NSAID use significantly decreased with increase in the age of the patients and increase in eGFR and those among hepatitis $\mathrm{C}$ patients. On the contrary, NSAID use was significantly higher among working, hypertensive, and osteoarthritis patients (Table 4).

\section{Discussion}

In this cross-sectional study of 350 pre-ESRD patients recruited from the Alexandria Main University hospital, the prevalence of NSAID usage was $65.7 \%$. There was a gradient increase in NSAID use through CKD stages with a prevalence of $2.6 \%$ in stage $2,9.1 \%$ in stage $3 a$, $27 \%$ in stage $3 \mathrm{~b}$, and $61.3 \%$ in stage 4 . Ketoprofen was the most commonly used drug. In addition, prolonged use of NSAIDs was related to reduction of eGFR.

The use of NSAIDs has been reported to range between 8.9 and $69.2 \%$ [8-13]. Variations in the NSAID use in many studies could be explained by differences in the regulations on NSAID purchase and its availability in different countries, with the absence of restricted laws on the consumption of drugs, which encourages patients to self-treat their symptoms and signs, especially pain 


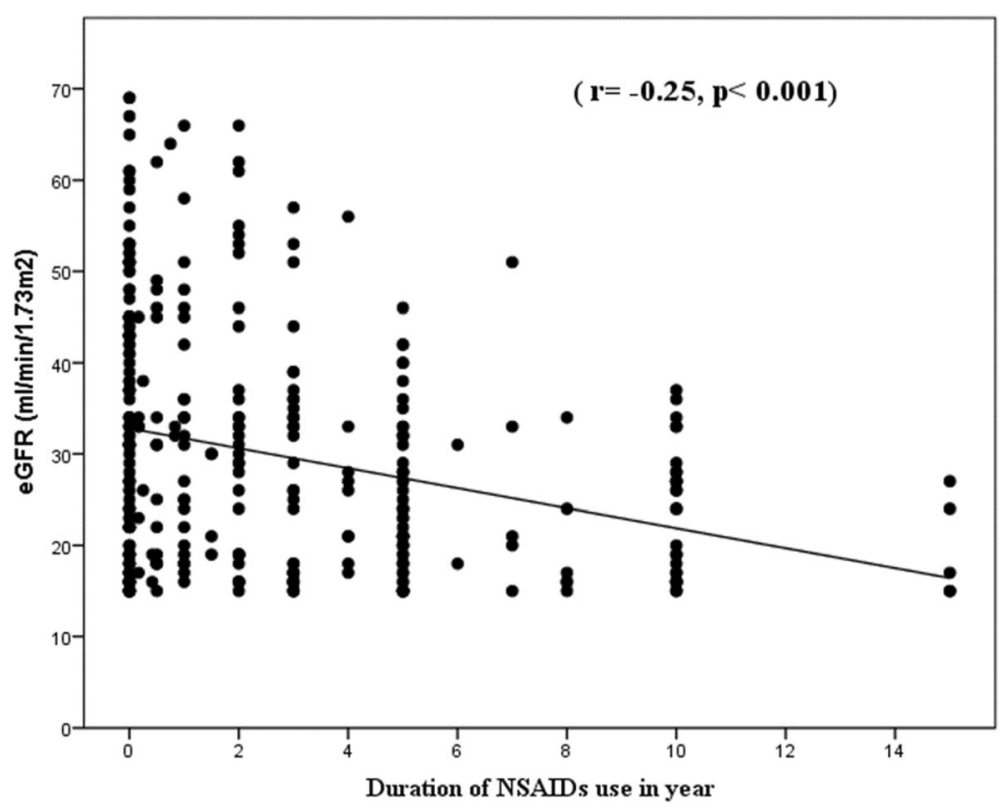

Fig. 2 Correlation between the duration of NSAID use and eGFR

$[14,15]$. Moreover, the silent nature of CKD and unawareness of the NSIAD complications predispose to the late diagnosis, with the inappropriate use of drugs $[16,17]$. In addition, the high use of NSAIDs may indicate that clinicians tend to disregard evaluating the renal functions of patients when prescribing NSAIDs especially in high-risk group patients or they may want to achieve a better quality of life in some comorbid conditions warranting the use of NSAIDs despite the inherent risk.

Consistent with reports from other studies $[9,18,19]$, headache was the most reported reason of NSAID use, followed by generalized pain and joint pain. Renal patients can experience pain as a result of several conditions and

Table 3 Knowledge of CKD patients about adverse effects of NSAIDs (Alexandria Main University Hospital, Egypt, 2016)

\begin{tabular}{lll}
\hline Knowledge about adverse effects & Frequency $(n=350)$ & Percent \\
\hline NSAIDs have adverse effects & 34 & 9.7 \\
No & 130 & 37.1 \\
Yes & 186 & 53.2
\end{tabular}

Do not know

Type of adverse effects $(n=130)^{a}$

Kidney problems

\begin{tabular}{lll} 
GIT problems & 72 & 55.4 \\
Liver problems & 59 & 45.4 \\
Do not know & 25 & 19.2 \\
Heart problems & 13 & 10.0 \\
& 3 & 2.3 \\
\hline
\end{tabular}

GIT gastrointestinal tract

${ }^{a}$ Non-mutually exclusive pathophysiological mechanisms. Osteodystrophy, osteoarthritis, calciphylaxis, and peripheral neuropathy may develop as consequence of the progressive course of CKD. Pain is also related to comorbidities such as peripheral vascular disease, cardiovascular disease, diabetic neuropathy, osteoporosis/osteopenia, and inflammatory/immunological diseases [20-22]. Their need for analgesia presents a serious challenge to clinicians and requires special considerations to achieve pain relief without causing toxicity [21].

Although it has been known that NSAIDs inhibit the therapeutic effect of RAAS inhibitors and diuretics (triple whammy), it was noted from the current study that many CKD patients who used NSAIDs were also receiving RAAS inhibitors (23\%), diuretics $(8.3 \%)$, or both (6.1\%). A similar problem was reported by Plantinga et al. in the USA [23]. They found that among CKD patients who had prescriptions for NSAIDs, 16\% had RAAS inhibitor prescriptions and $20 \%$ had diuretic prescriptions.

The pattern of NSAIDs in the current study showed that $40 \%$ of CKD patients used NSAIDs twice a week, $20.4 \%$ three times a week, and $22 \%$ every day. A considerable percentage used NSAIDs for a period exceeding 3 years or from 1 to 3 years $(46.1 \%$ and $41.7 \%$ respectively). Only $12.2 \%$ of CKD patients used NSAIDs for less than 1 year. In other studies, the pattern of NSAID use was different. In Poland (2016) [18], 12.2\% of CKD (stages 1-4) used NSAIDs few times a week, 14.8\% few times a month, and $7.7 \%$ every day. In Southern Italy (2014) [13], more than one third (35.6\%) of CKD patients were treated with NSAIDs for a period exceeding 
Table 4 Multiple logistic regression analysis for the factors affecting NSAID use among CKD patients, Alexandria Main University Hospital, 2016

\begin{tabular}{|c|c|c|c|c|c|}
\hline \multirow{2}{*}{$\begin{array}{l}\text { Independent } \\
\text { variable }\end{array}$} & \multirow[t]{2}{*}{ Unit of the variable } & \multirow[t]{2}{*}{ OR } & \multicolumn{2}{|l|}{$\underline{95 \% \mathrm{Cl}}$} & \multirow[t]{2}{*}{$p$ value } \\
\hline & & & Lower limit & Upper limit & \\
\hline Age & 1 year & 0.96 & 0.93 & 0.99 & $0.01^{*}$ \\
\hline Gender & $0=$ female, $1=$ male & 1.07 & 0.26 & 4.43 & 0.93 \\
\hline Working status & $0=$ not working, $1=$ working & 2.66 & 1.19 & 5.95 & $0.02^{*}$ \\
\hline Smoking & $0=$ non-smoker, $1=$ smoker & 1.03 & 0.43 & 2.51 & 0.94 \\
\hline eGFR & $1 \mathrm{ml} / \mathrm{min} / 1.73 \mathrm{~m}^{2}$ & 0.97 & 0.95 & 0.99 & $0.01^{*}$ \\
\hline Hypertension & $0=$ no, $1=$ yes & 2.60 & 1.27 & 5.35 & $0.008^{*}$ \\
\hline Osteoarthritis & $0=$ no, $1=$ yes & 6.34 & 2.03 & 19.78 & $<0.001^{*}$ \\
\hline Hepatitis C & $0=$ no, $1=$ yes & 0.15 & 0.06 & 0.40 & $<0.001^{*}$ \\
\hline
\end{tabular}

*Significant at $p<0.05$

90 days and almost $16.5 \%$ for more than 6 months. In USA (2011), Plantinga et al. [23] showed that $65 \%$ of CKD (stages 1 or 2 ) and $64.4 \%$ of CKD (stages 3 or 4 ) were long-term users of NSAIDs (1 year or longer).

A significant association between eGFR and NSAID use was found in the present study as the odds of NSAID use decreased by $3 \%$ for every $1 \mathrm{ml} / \mathrm{min} / 1.73 \mathrm{~m}^{2}$ increase in eGFR. This association is consistent with what was reported in several studies. Senevirathna et al. [24] conducted a cohort study among 143 CKD patients of uncertain etiology to determine the possible factors associated with the progression and mortality of CKD. They reported that NSAIDs were a major individual factor for disease progression. Kuo and his colleagues [25] carried out a cohort study using a nationally representative sample of 19,163 newly diagnosed CKD patients to study the risk of various analgesics use on the progression of CKD. CKD patients using non-selective NSAIDs had an increased risk of CKD stage 5 . The trends toward higher risk with increasing exposure dose were significant for all classes of analgesics.

\subsection{Limitations of the study}

Our study has limitations. First, it is a cross-sectional study, so we were not able to study the causal association between NSAID use and CKD progression. Second, our main definition did not include the most commonly used over-the-counter analgesics-acetaminophen and aspirin-because of their relatively low nephrotoxicity and indications for pain and cardiovascular prevention, respectively. Third, participants with chronic pain may over- or underestimate the duration and frequency of NSAID use. This could be due to high illiteracy rate. In addition, we did not have information on clinician recommendation, or detailed dosage and frequency. Fourth, there is the possibility of CKD misclassification, particularly for earlier stages. Finally, information on comorbid conditions was taken by clinical history.

\section{Conclusion}

As there are no available previous studies on the use of NSAID in kidney disease patients in Egypt, this study provided important information that would decrease the gap in knowledge about the use of NSAID in Egypt. It also has important implications. It reflects the importance of communicating the effects of NSAID use especially their nephrotoxicity and potential interactions with RAAS inhibitors and diuretics to physicians, other prescribers of medication, and the community through training courses and workshops.

\section{Acknowledgements}

We would like to thank the patients for their participation and staff at the Internal Medicine Department, Alexandria Main University Hospital. We would also like to acknowledge that part of this work was accepted as an abstract at the ERA-EDTA congress, 2018 in Copenhagen-Denmark.

\section{Funding}

None.

Availability of data and materials

Please contact the author for data requests.

\section{Authors' contributions}

$S A E, R H, Y N$, and SS conceptualized and designed the study. SAE, RH, YN, and SS built the data collection tool and supervised the data collection. SAE, IW, and RH analyzed and interpreted the data. SAE, RH, IW, and YN wrote the first draft of the manuscript. SAE, RH, YN, IW, and SS revised and critically read the manuscript. All of the authors read and approved the final manuscript.

\section{Ethics approval and consent to participate}

The study was approved by the Ethics Committee of the High Institute of Public Health. All methods were performed in accordance with the International Guidelines for Research Ethics. Verbal consent was obtained from each study participant after explanation of the purpose and benefits of the study. Verbal consent was used as the study was based on records without taking any biological samples or giving any investigational medicine, so it did not introduce more than minimal risk to the study patients. Anonymity and confidentiality of participants were maintained. 


\section{Consent for publication}

All authors agree on the manuscript and give consent for it to be published.

\section{Competing interests}

The authors declare that they have no competing interests.

\section{Publisher's Note}

Springer Nature remains neutral with regard to jurisdictional claims in published maps and institutional affiliations.

\section{Author details}

'Department of Epidemiology, High Institute of Public Health, Alexandria University, 165 ElHorreya Avenue, ElHadara, Alexandria, Egypt. ${ }^{2}$ Ministry of Health, Alexandria, Egypt. ${ }^{3}$ Department of Internal Medicine (Nephrology unit), Faculty of Medicine, Alexandria University, Alexandria, Egypt.

Received: 6 November 2018 Accepted: 20 December 2018

Published online: 30 January 2019

\section{References}

1. Levin A, Stevens PE, Bilous RW, Coresh J, De Francisco AL, De Jong PE, et al. Kidney Disease: Improving Global Outcomes (KDIGO) CKD Work Group. KDIGO 2012 clinical practice guideline for the evaluation and management of chronic kidney disease. Kidney Int Suppl. 2013:3(1):1-150.

2. Harirforoosh S, Asghar W, Jamali F. Adverse effects of nonsteroida antiinflammatory drugs: an update of gastrointestinal, cardiovascular and renal complications. J Pharm Pharm. 2014;16(5):821-47.

3. Naughton CA. Drug-induced nephrotoxicity. Am Fam Physician. 2008;78(6): 743-50

4. Perazella MA. Renal vulnerability to drug toxicity. Clin J Am Soc Nephrol. 2009:4(7):1275-83.

5. Hörl WH. Nonsteroidal anti-inflammatory drugs and the kidney. Pharmaceuticals. 2010;3(7):2291-321.

6. Nayak-Rao S. Achieving effective pain relief in patients with chronic kidney disease: a review of analgesics in renal failure. J Nephrol. 2011:24(1):35-40.

7. Loboz KK, Shenfield GM. Drug combinations and impaired renal functionthe 'triple whammy'. Br J Clin Pharmacol. 2005;59(2):239-43.

8. Bilge U, Sahin G, Unluoglu I, Ipek M, Durdu M, Keskin A. Inappropriate use of nonsteroidal anti-inflammatory drugs and other drugs in chronic kidney disease patients without renal replacement therapy. Ren Fail. 2013;35(6): 906-10.

9. Hull S, Mathur R, Dreyer G, Yaqoob MM. Evaluating ethnic differences in the prescription of NSAIDs for chronic kidney disease: a cross-sectional survey of patients in general practice. Br J Gen Pract. 2014;64(624):e448-e55.

10. Zhan M, Peter WLS, Doerfler RM, Woods CM, Blumenthal JB, Diamantidis CJ, et al. Patterns of NSAIDs use and their association with other analgesic use in CKD. Clin J Am Soc Nephrol. 2017;12:1778-86.

11. Adams RJ, Appleton SL, Gill TK, Taylor AW, Wilson DH, Hill CL. Cause for concern in the use of non-steroidal anti-inflammatory medications in the community--a population-based study. BMC Fam Pract. 2011;12:70.

12. Meuwesen WP, Du Plessis JM, Burger JR, Lubbe MS, Cockeran M. Prescribing patterns of non-steroidal anti-inflammatory drugs in chronic kidney disease patients in the South African private sector. Int J Clin Pharm. 2016;38(4):863-9.

13. Ingrasciotta Y, Sultana J, Giorgianni F, Caputi AP, Arcoraci V, Tari DU, et al. The burden of nephrotoxic drug prescriptions in patients with chronic kidney disease: a retrospective population-based study in Southern Italy. PLoS One. 2014;9(2):e89072.

14. Hawton K, Simkin S, Deeks J, Cooper J, Johnston A, Waters K, et al. UK legislation on analgesic packs: before and after study of long term effect on poisonings. BMJ. 2004;329(7474):1076

15. Hughes CM, McElnay JC, Fleming GF. Benefits and risks of self medication. Drug Saf. 2001;24(14):1027-37.

16. Rothberg MB, Kehoe ED, Courtemanche AL, Kenosi T, Pekow PS, Brennan $\mathrm{MJ}$, et al. Recognition and management of chronic kidney disease in an elderly ambulatory population. J Crit Care Med. 2008;23(8):1125.

17. Vassalotti JA, Stevens LA, Levey AS. Testing for chronic kidney disease: a position statement from the National Kidney Foundation. AJKD. 2007:50(2): 169-80.
18. Heleniak Z, Cieplińska M, Szychliński T, Rychter D, Jagodzińska K, Kłos A, et al. Nonsteroidal anti-inflammatory drug use in patients with chronic kidney disease. J Nephrol. 2017;30(6):781-6.

19. Kaewput W, Disorn P, Satirapoj B. Selective cyclooxygenase-2 inhibitor use and progression of renal function in patients with chronic kidney disease: a single-center retrospective cohort study. Int J Nephrol Renovasc Dis. 2016;9: 273-8.

20. Davison SN, Koncicki H, Brennan F. Pain in chronic kidney disease: a scoping review. Semin Dial. 2014;27(2):188-204

21. Kafkia T, Chamney M, Drinkwater A, Pegoraro M, Sedgewick J. Pain in chronic kidney disease: prevalence, cause and management. J Ren Care. 2011;37(2):114-22.

22. Santoro D, Satta E, Messina S, Costantino G, Savica V, Bellinghieri G. Pain in end-stage renal disease: a frequent and neglected clinical problem. Clin Nephrol. 2013;79(Suppl 1):S2-S11.

23. Plantinga L, Grubbs V, Sarkar U, Hsu C-y, Hedgeman E, Robinson B, et al. Nonsteroidal anti-inflammatory drug use among persons with chronic kidney disease in the United States. Ann Fam Med. 2011;9(5):423-30.

24. Senevirathna L, Abeysekera T, Nanayakkara S, Chandrajith R, Ratnatunga N, Harada $\mathrm{KH}$, et al. Risk factors associated with disease progression and mortality in chronic kidney disease of uncertain etiology: a cohort study in Medawachchiya. Sri Lanka Environ Health Prev Med. 2012:17(3):191-8.

25. Kuo HW, Tsai SS, Tiao MM, Liu YC, Lee I-m, Yang CY. Analgesic use and the risk for progression of chronic kidney disease. Pharmacoepidemiol Drug Saf. 2010;19(7):745-51

\section{Submit your manuscript to a SpringerOpen ${ }^{\circ}$ journal and benefit from:}

- Convenient online submission

Rigorous peer review

- Open access: articles freely available online

- High visibility within the field

- Retaining the copyright to your article

Submit your next manuscript at $\boldsymbol{\nabla}$ springeropen.com 